\title{
Pharmacological effects of traditional herbal plant garlic (Allium sativum): A review
}

\section{Paudel KR}

Keshab Raj Paudel, Assistant Professor, Department of Pharmacology, Kathmandu Medical College Teaching Hospital, Kathmandu Nepal

\begin{abstract}
This study aimed to review the different pharmacological effects of garlic. Garlic, Allium sativum, is a herbal plant which has been used in different food preparations since long time. Many studies have shown that allicin is the main compound in garlic which is generated from alliin with the help of alliinase enzyme and is responsible for many pharmacological effects. Different studies have shown that garlic has pharmacological effects such as antihypertensive, antihypercholesterolaemic, antiplatelet, hypoglycaemic, cardioprotective, antimicrobial, antineoplastic, etc. However, studies in the literature have some conflicting findings and meta-analyses are also slightly different for different effects. Despite these findings, most of the studies, including meta-analyses, have shown significant antihypertensive and hypolipidaemic effects of garlic. Based on the data in the literature, regular dietary consumption of raw garlic, two to four grams, equivalent to one clove of garlic, or $600-900 \mathrm{mg}$ garlic powder per day, if not contraindicated, may be effective for different beneficial pharmacological effects.
\end{abstract}

Key words: Allicin, Alliin, Allium sativum, Garlic.

\section{INTRODUCTION}

4 llium sativum, commonly known as garlic, is used 1 as one of common components of foods and condiments ${ }^{1}$. Many reports in the literature have shown that $A$. sativum has variety of pharmacological activities such as antihypertensive, antihypercholesterolaemic, cardioprotective, antiplatelet, hypoglycaemic, antimicrobial, antineoplastic, etc. though all the data in the different researches are not concordant with each other. Garlic contains alliin, allicin, diallyl disulphide, S-allylcysteine and diallyl trisulfide organosulfur compounds and allicin is responsible for characteristic garlic odour ${ }^{1,2-5}$. Out of these compounds, allicin is the most studied compound responsible for the different types of pharmacological effects ${ }^{2}$. Alliin is the precursor of allicin which is produced by the action of alliinase enzyme. This enzyme may be deactivated by gastric juice. So, enteric coated tablets of garlic are recommended for the therapeutic uses to inhibit the gastric inactivation of enzyme so that generation of allicin from alliin is

Address for correspondence

Dr. Keshab Raj Paudel

Assistant Professor

Department of Pharmacology

Kathmandu Medical College and Teaching Hospital,

Kathmandu, Nepal

E-mail: keshabpaudel@gmail.com not affected ${ }^{6}$. Allicin is hydrophobic and crosses the biological barrier easily and undergoes metabolic pathway instantly to produce different pharmacological effects ${ }^{7}$.

\section{METHODS}

Cochrane library, MEDLINE/PUBMED central through HINARI and open access journals were searched for garlic Allicin, Alliin and Allium sativum for the published data in the period of 1990 to 2014 . Besides, related chapter in the text books were also consulted. Studies with relevant and significant findings were included in the study. Depending upon the different studies, the formulation of the garlic was different such as enteric coated tablets, dried garlic powder, standardized dehydrated garlic preparation and raw garlic. Dose of the formulation and duration of study differed from study to study.

\section{BODY}

There is no unanimous consensus vis $a$ vis effective ingredient in the garlic for various pharmacological effects. However, many garlic researchers believe that allicin is the major ingredient which is responsible for various potential clinical effects ${ }^{8}$. Investigations are underway to clearly delineate the exact mechanism of action of $A$ sativum. Similarly, some studies have 
tried to explore the metabolic pathways for various pharmacological activities which are as follows: Allicin may decrease oxidative stress (by decreasing reactive oxygen species and stimulating the production of glutathione ${ }^{7}$, increase nitric oxide bioavailability and hydrogen sulfide production, decrease angiotensin converting enzyme activity, expression of nuclear factor kappa-light-chain-enhancer of activated $B$ cells $(N F-\kappa B$ which plays key role in immune response to different stimuli) and the proliferation of vascular smooth muscle cells which are associated with pathogenesis (mainly atherosclerosis) of hypertension?. Organosulfur compounds from garlic are converted by red blood cells into hydrogen sulfide which dilates vascular smooth muscle cells and decrease total peripheral resistance ${ }^{3}$. Garlic also shows antiplatelet effects which is due to inhibition of thromboxane synthesis and fibrinolytic activity ${ }^{6}$. Antioxidant and tumour growth inhibition may be responsible for the antineoplastic growth of garlic ${ }^{4}$. Hypoglycaemic effect of garlic is due to the presence of volatile organosulfur compounds like alliin, allicin, diallyl disulfide, diallyl trisulfide, diallyl sulfide, S-allyl cysteine, ajoene and allyl mercaptan ${ }^{5}$. A randomised controlled clinical trial on pro-inflammatory cytokines has shown that tissue necrosis factor alfa (TNF $\alpha$ ) has decreased significantly in garlic treated group pre and post measurement in postmenopausal osteoporotic females though there was no significant effect on interleukin-1 (IL-1) and interleukin-6 (IL-6) which, along with TNF $\alpha$ are involved in post-menopausal osteoporosis ${ }^{10}$.

\section{EFFECTS OF GARLIC}

\section{Antihypertensive effect}

Meta-analysis by Reinhart et al showed that garlic reduced blood pressure only in those patients with elevated systolic blood pressure. It reduced systolic blood pressure by $16.3 \mathrm{~mm} \mathrm{Hg}$ (95\% confidence interval 6.2 to 26.5) and diastolic blood pressure by $9.3 \mathrm{~mm}$ $\mathrm{Hg}$ (95\% confidence interval 5.3 to 13.3 ) compared to placebo ${ }^{11}$.

\section{Hypolipidaemic effect}

Based on animal data, Allicin decreased blood cholesterol and triglycerides and caused a significant reduction in the hepatic cholesterol storage ${ }^{12}$. Metaanalyses based on clinical trials suggest that regardless of garlic preparation and compared to placebo garlic reduces total blood cholesterol $(7.2 \mathrm{mg} / \mathrm{dl}, 95 \% \mathrm{Cl}$ : $1.2-13.5)$ and low density cholesterol $(6.2 \mathrm{mg} / \mathrm{dl}, 95 \%$ $\mathrm{Cl}$ : 0.77-11.6) levels though there are variations in the findings ${ }^{8}$. However, another meta-analysis of 29 clinical trials shows that garlic reduces total cholesterol (TC) and triglyceride (TG) levels only marginally (TC- $3.42 \mathrm{mg} / \mathrm{dl}$, range $1.08-5.94 \mathrm{mg} / \mathrm{dl}$ and TG- $1.98 \mathrm{mg} / \mathrm{dl}$, range $1.08-$ $3.42 \mathrm{mg} / \mathrm{dl}$ ), though significantly, without significant effect on low density and high density lipopropteins ${ }^{13}$.

\section{Antiplatelet effect}

Studies have shown that there is significant reduction in platelet aggregation after garlic treatment ${ }^{7,8}$. Garlic also reduces epinephrine induced platelet aggregation ${ }^{14}$. Patients taking oral anticoagulants like warfarin may experience increased bleeding episodes. It is advisable to stop garlic administration one week prior to any surgical intervention.

\section{Hypoglycaemic effect}

Short term clinical trials have shown significant reduction in the blood glucose level in non-diabetic persons compared to placebo ${ }^{8}$. Other reports on human studies have also shown the hypoglycemic effects of garlic. The antidiabetic effects of garlic are mainly due to the volatile sulfur compounds. Garlic has been shown to be effective in reducing insulin resistance as well ${ }^{5}$.

\section{Cardioprotective effect}

When compared to garlic treated group and placebo group, in garlic treated group 11 deaths and 15 reinfarctionswerenoted in 222 prior myocardial infarction patients in a three year study whereas 20 deaths and 22 reinfarctions in 210 placebo treated patients ${ }^{8}$. Garlic reduces norepinephrine induced cardiomyopathy ${ }^{15}$ and reverses atherosclerosis ${ }^{16}$. Studies have shown allicin provides cardio-protective activity by causing vasodilatation and decreasing different pathogenicities of coronary artery disease, including cardiac hypertrophy, angiogenesis, platelet aggregation, hyperlipidaemia and hyperglycaemia ${ }^{7,17}$. Cardioprotective effect of garlic may be the combined beneficial effects of vasodilatory, antihypertensive, hypolipidaemic, antiplatelet, antioxidant activities and inhibition of noradrenaline induced cardiomyopathy $y^{7,8,18-20}$.

\section{Effect on peripheral vascular disease}

Significant increase in pain-free walking distance (relieve of intermittent claudication) has been reported after the administration of garlic extracts in different clinical trials ${ }^{8}$. However, long-term study is required for the clinical relevance of garlic in peripheral vascular diseases ${ }^{21}$.

\section{Antimicrobial effect}

Compared to flucunazole, allicin reduced the bio-film of Candida albicans significantly in the experimental set up by inhibiting the gene hyphal wall protein 1 (HWP1-is a adhesive glycoprotein present on the 
surface of Candida albicans) which is responsible for the aggregation of organism to form biofilm. Allicin also causes membrane disruption to inhibit the growth of the fungus ${ }^{22}$. Allicin showed an antifungal activity against mycoses-causing dermatophytes with similar activity to ketoconazole ${ }^{23}$. Oral pathogens involved in the pathogenesis of dental caries and periodontitis such as Streptococcus mutans, S. sobrinus, Actinomyces oris, Aggregatibacter actinomycetemcomitans and Fusobacterium nucleatum are also inhibited by allicin ${ }^{24}$.

\section{Antineoplastic effect}

Animal studies have shown that garlic inhibits procarcinogens for esophageal, stomach, colon, lung and breast cancer. Human clinical and epidemiological studies have also the evidence of chemoprotective effects of garlic ${ }^{4,6}$.

\section{Effect on post-menopausal osteoporosis}

Garlic may decrease postmenopausal osteoporosis in the females by modulating proinflammatory cytokins IL1, IL-6 and TNF- $\alpha$. However, more research is required ${ }^{10}$.

\section{Neuroprotective effect}

Data on animal study have shown that allicin may cause neuroprotection in ischaemia reperfusion injury to the spinal cord by improving mitochondrial function ${ }^{25}$.

\section{Effect against common cold}

One clinical trial has shown that regular garlic intake may decrease the prevalence of common cold. However, this finding is inconclusive and needs more studies ${ }^{26}$.

\section{SIDE EFFECTS}

Characteristic garlic smell has been reported (28\%-garlic group versus $12 \%$ - placebo group) more commonly by different studies ${ }^{8,21}$. Other side effects include body odour, abdominal pain, anorexia, flatulence and allergic reactions though they are not statistically significant ${ }^{6,8}$.

\section{DOSAGE AND ADMINISTRATION}

Various methods and different forms of garlic preparation may result in the significant difference in the garlic ingredients in the final composition. At low gastric $\mathrm{pH}$, alliinase enzyme which is required to produce allicin from alliin gets denaturated and becomes inactive so the allicin generation is affected ${ }^{8}$. For this reason, entericcoated garlic preparations are suggested. However, dried garlic powders in which content of allicin is standarised are recommended in the dose range of 600$900 \mathrm{mg}$ per day which is equivalent to one clove of raw garlic (2-4 gm) ${ }^{6,15}$.

\section{PRECAUTION}

It is better to avoid raw dietary garlic in take by the patients who are under anticoagulant and/or antiplatelet therapy (warfarin, aspirin, clopidogrel, ticlopidine, etc). It is recommended that persons who are under either garlic supplement or high dietary raw garlic consumption avoid garlic intake one week before any surgical intervention ${ }^{6,8}$.

\section{CONCLUSION}

Garlic has variety of beneficial pharmacological effects such as antihypertensive, hypolipidaemic, antiplatelet, hypoglycaemic, cardioprotective, antineoplastic, antimicrobial activities, etc. Dietary inclusion of one clove of garlic per day may help get benefitted from various effects of garlic.

\section{REFERENCES}

1. Aviello G, Abenavoli L, Borrelli F, Capasso R, Izzo AA, Lembo $F$, et al. Garlic: empiricism or science? Nat Prod Commun. 2009;4(12):1785-96.

2. Mikaili P, Maadirad S, Moloudizargari M, Aghajanshakeri S, Sarahroodi S. Therapeutic Uses and Pharmacological Properties of Garlic, Shallot, and Their Biologically Active Compounds. Iran J Basic Med Sci. 2013;16(10):1031-48.

3. Ginter E, Simko V. Garlic (Allium sativum L.) and cardiovascular diseases. Bratisl Lek Listy. 2010;111(8):452-6.

4. Thomson M, Ali M. Garlic [Allium sativum]: a review of its potential use as an anti-cancer agent. Curr Cancer Drug Targets. 2003;3(1):67-81.
5. Padiya R, Banerjee SK. Garlic as an anti-diabetic agent: recent progress and patent reviews. Recent Pat Food Nutr Agric. 2013;5(2):105-27.

6. Dennehy CE, Tsourounis C. Botanicals (Herbal Medications) and nutritional supplements. In Katzung BG, editor. Basic and clinical pharmacology. 12th ed. USA: McGraw-Hills Companies; 2012. p. 1125-37.

7. Chan JY, Yuen AC, Chan RY, Chan SW. A review of the cardiovascular benefits and antioxidant properties of allicin. Phytother Res. 2013;27(5):637-46.

8. Ackermann RT, Mulrow CD, Ramirez G, Gardner CD, Morbidoni L, Lawrence VA. Garlic shows promise for improving some cardiovascular risk factors. Arch Intern Med. 2001;161:813-24. 
9. Shouk R, Abdou A, Shetty K, Sarkar D, Eid AH. Mechanisms underlying the antihypertensive effects of garlic bioactives. Nutr Res. 2014;34(2):10615.

10. Mozaffari-Khosravi $H$, Hesabgar HA, Owlia MB, Hadinedoushan $\mathrm{H}$, Barzegar K, Fllahzadeh MH. The effect of garlic tablet on pro-inflammatory cytokines in postmenopausal osteoporotic women: a randomized controlled clinical trial. J Diet Suppl. 2012;9(4):262-71.

11. ReinhartKM,Coleman $\mathrm{Cl}$, Teevan C,VachhaniP, White CM. Effects of garlic on blood pressure in patients with and without systolic hypertension: a metaanalysis. Ann Pharmacother. 2008;42(12):1766-71.

12. Lu Y, He Z, Shen X, Xu X, Fan J, Wu S, Zhang D. Cholesterol-lowering effect of allicin on hypercholesterolemic ICR mice. Oxid Med Cell Longev. 2012;2012:489-690.

13. Reinhart KM, Talati $\mathrm{R}$, White $\mathrm{CM}$, Coleman $\mathrm{Cl}$. The impact of garlic on lipid parameters: a systematic review and meta-analysis. Nutr Res Rev. 2009;22(1):39-48.

14. Steiner $M$, Lin RS. Change in platelet function and susceptibility of lipoproteins to oxidation associated with the administration of aged garlic extract. J cardiovasc Pharmacol. 1998;31:904-8.

15. Louis XL, Murphy R, Thandapilly SJ, Yu L, Netticadan T. Garlic extracts prevent oxidative stress, hypertrophy and apoptosis in cardiomyocytes: a role for nitric oxide and hydrogen sulfide. BMC Complement Altern Med. 2012;12:140.

16. Koscielny J, Klussendorf D, Latza R, Schmitt R, Radtke $\mathrm{H}$, Siegel $\mathrm{G}$, et al. The antiatherosclerotic effect of Allium sativum. Atherosclerosis. 1999;144:237-49.

17. Tattelman E. Health effects of garlic. Am Fam Physician. 2005 Jul 1;72(1):103-6.

18. Neil HA, Silagy CA, Lancaster $T$, Hodgeman J, Vos K, Moore JW, Jones L, Cahill J, Fowler GH.
Garlic powder in the treatment of moderate hyperlipidaemia: a controlled trial and metaanalysis. J R Coll Physicians London. 1996;30(4):32934.

19. Silagy C, Neil A. Garlic as a lipid lowering agent--a meta-analysis. J R Coll Physicians London. 1994;28(1):39-45.

20. Elkayam A, Peleg E, Grossman E, Shabtay Z, Sharabi $Y$. Effects of allicin on cardiovascular risk factors in spontaneously hypertensive rats. Isr Med Assoc J. 2013;15(3):170-3.

21. Jepson RG, Kleijnen J, Leng GC. Garlic for peripheral arterial occlusive disease. Cochrane Database of Systematic Reviews 2013, Issue 4. Art. No.: CD000095

22. Khodavandi A, Harmal NS, Alizadeh F, Scully OJ, Sidik SM, Othman F, Sekawi Z, Ng KP, Chong PP. Comparison between allicin and fluconazole in Candida albicans biofilm inhibition and in suppression of HWP1 gene expression. Phytomedicine. 2011 Dec 15;19(1):56-63.

23. Aala F, Yusuf UK, Jamal F, Rezaie S. Antimicrobial effects of allicin and ketoconazole on trichophyton rubrum under in vitro condition. Braz J Microbiol. 2012;43(2):786-92.

24. Bachrach G, Jamil A, Naor R, Tal G, Ludmer Z, Steinberg D. Garlic allicin as a potential agent for controlling oral pathogens. J Med Food. 2011;14(11):1338-43.

25. Zhu JW, Chen T, Guan J, Liu WB, Liu J. Neuroprotective effects of allicin on spinal cord ischemia-reperfusion injury via improvement of mitochondrial function in rabbits. Neurochem Int. 2012;61(5):640-8.

26. Lissiman E, Bhasale AL, Cohen M. Garlic for the common cold. Cochrane Database Syst Rev. 2012;3:CD006206. 